\title{
Cross-sectional Comparison of the Epidemiology of DSM-5 Generalized Anxiety Disorder Across the Globe
}

\begin{abstract}
Ayelet Meron Ruscio, PhD; Lauren S. Hallion, PhD; Carmen C. W. Lim, MSc; Sergio Aguilar-Gaxiola, MD, PhD; Ali Al-Hamzawi, MD; Jordi Alonso, MD, PhD; Laura Helena Andrade, MD, PhD; Guilherme Borges, ScD; Evelyn J. Bromet, PhD; Brendan Bunting, PhD; José Miguel Caldas de Almeida, MD, PhD; Koen Demyttenaere, MD, PhD; Silvia Florescu, MD, PhD; Giovanni de Girolamo, MD;

Oye Gureje, MD, PhD, FRCPsych; Josep Maria Haro, MD, PhD; Yanling He, MD; Hristo Hinkov, MD, PhD; Chiyi Hu, MD, PhD; Peter de Jonge, PhD; Elie G. Karam, MD; Sing Lee, MB, BS; Jean-Pierre Lepine, MD; Daphna Levinson, PhD; Zeina Mneimneh, PhD; Fernando Navarro-Mateu, MD, PhD; José Posada-Villa, MD; Tim Slade, PhD; Dan J. Stein, FRCP, PhD; Yolanda Torres, MPH; Hidenori Uda, MD; Bogdan Wojtyniak, ScD; Ronald C. Kessler, PhD; Somnath Chatterji, MD; Kate M. Scott, PhD
\end{abstract}

IMPORTANCE Generalized anxiety disorder (GAD) is poorly understood compared with other anxiety disorders, and debates persist about the seriousness of this disorder. Few data exist on GAD outside a small number of affluent, industrialized nations. No population-based data exist on GAD as it is currently defined in DSM-5.

OBJECTIVE To provide the first epidemiologic data on DSM-5 GAD and explore cross-national differences in its prevalence, course, correlates, and impact.

DESIGN, SETTING, AND PARTICIPANTS Data come from the World Health Organization World Mental Health Survey Initiative. Cross-sectional general population surveys were carried out in 26 countries using a consistent research protocol and assessment instrument. A total of 147261 adults from representative household samples were interviewed face-to-face in the community. The surveys were conducted between 2001 and 2012. Data analysis was performed from July 22, 2015, to December 12, 2016.

MAIN OUTCOMES AND MEASURES The Composite International Diagnostic Interview was used to assess GAD along with comorbid disorders, role impairment, and help seeking.

RESULTS Respondents were 147261 adults aged 18 to 99 years. The surveys had a weighted mean response rate of $69.5 \%$. Across surveys, DSM-5 GAD had a combined lifetime prevalence (SE) of $3.7 \%(0.1 \%), 12$-month prevalence of $1.8 \%(0.1 \%)$, and 30 -day prevalence of $0.8 \%(0)$. Prevalence estimates varied widely across countries, with lifetime prevalence highest in high-income countries (5.0\% [0.1\%]), lower in middle-income countries $(2.8 \%$ [0.1\%]), and lowest in low-income countries (1.6\% [0.1\%]). Generalized anxiety disorder typically begins in adulthood and persists over time, although onset is later and clinical course is more persistent in lower-income countries. Lifetime comorbidity is high (81.9\% [0.7\%]), particularly with mood (63.0\% [0.9\%]) and other anxiety (51.7\% [0.9\%]) disorders. Severe role impairment is common across life domains (50.6\% [1.2\%]), particularly in high-income countries. Treatment is sought by approximately half of affected individuals (49.2\% [1.2\%]), especially those with severe role impairment $(59.4 \%$ [1.8\%]) or comorbid disorders (55.8\% [1.4\%]) and those living in high-income countries (59.0\% [1.3\%]).

CONCLUSIONS AND RELEVANCE The findings of this study show that DSM-5 GAD is more prevalent than DSM-IVGAD and is associated with substantial role impairment. The disorder is especially common and impairing in high-income countries despite a negative association between GAD and socioeconomic status within countries. These results underscore the public health significance of GAD across the globe while uncovering cross-national differences in prevalence, course, and impairment that require further investigation.

JAMA Psychiatry. 2017;74(5):465-475. doi:10.1001/jamapsychiatry.2017.0056 Published online March 15, 2017.
Supplemental content

Author Affiliations: Author affiliations are listed at the end of this article.

Corresponding Author: Ayelet Meron Ruscio, PhD, Department of Psychology, University of Pennsylvania, The Stephen A. Levin Building, 425 S University Ave, Philadelphia, PA 19104 (ruscio@psych.upenn.edu). 
U nderstanding of generalized anxiety disorder (GAD) has lagged behind understanding of other anxiety disorders. ${ }^{1,2}$ Since its introduction in DSM-III, ${ }^{3}$ the GAD diagnosis has undergone frequent substantial revision, challenging efforts to accumulate a knowledge base for the disorder. Originally, GAD was considered a "wastebasket diagnosis" presumed to be associated with fairly modest impairment. ${ }^{4,5}$ Although GAD has evolved into a well-defined condition characterized by excessive, uncontrollable worry, the assumption that GAD is associated with relatively minimal impairment has persisted in some circles, with the term "worried well" sometimes used to describe affected individuals. ${ }^{1,6}$ This assumption may partially account for lower clinical and research attention to GAD than to other emotional disorders. ${ }^{7,8}$

Attention to GAD has been especially limited outside a small number of industrialized, affluent countries in which nearly all research on the disorder has been conducted. There is reason to suspect, however, that GAD may be important not only in affluent countries but also in other parts of the world. In fact, GAD might be more common and impairing in lower-income countries given the greater economic and political instability, insecurity of access to basic necessities, and uncertainty about the future that tend to characterize those countries. In line with this hypothesis, lower socioeconomic status is associated with greater mental illness within countries ${ }^{9,10}$; similar mechanisms could apply across countries as well.

Alternatively, GAD might be less prevalent and impairing in lower-income countries. A GAD diagnosis requires worries to be excessive, and this requirement may be met less often in countries where worry corresponds to realistic everyday concerns. Furthermore, other disorders have been observed to manifest more frequently through somatic than cognitive symptoms in non-Western countries, ${ }^{11,12}$ raising the possibility that GAD, which is centrally defined by a cognitive symptom (worry), may be less common in developing than developed countries. Finally, cross-cultural research on other chronic mental disorders suggests that prevalence is often lower and outcomes better in less developed countries, perhaps due to greater provision of support by family and community. ${ }^{13}$

We explored these competing hypotheses using data from the World Mental Health (WMH) Survey Initiative, ${ }^{14}$ a coordinated series of general population surveys carried out under the auspices of the World Health Organization (WHO). Two features of the surveys are noteworthy for the present study. First, data were collected in 26 countries of varying income levels. This diversity provided an opportunity to isolate universal characteristics of GAD from characteristics that vary across countries. Second, by lifting the DSM-IV hierarchy rule prohibiting the diagnosis of GAD during a mood disorder, the surveys were able to define GAD using DSM- 5 criteria. To our knowledge, these results represent the first community epidemiologic data on DSM-5 GAD.

\section{Methods}

Samples and Procedures

Respondents were 147261 adults, ranging in age from 18 to 99 years, who participated in the WMH surveys. Data from 29 sur-

\section{Key Points}

Question What are the patterns and correlates of DSM-5 generalized anxiety disorder throughout the world?

Findings In general population surveys of approximately 150000 adults in 26 countries, DSM- 5 generalized anxiety disorder has a combined lifetime prevalence of 3.7\%, 12-month prevalence of $1.8 \%$, and 30 -day prevalence of $0.8 \%$. The disorder is significantly more prevalent and impairing in high-income countries than in low- or middle-income countries.

Meaning DSM-5 generalized anxiety disorder is more prevalent than DSM-IV generalized anxiety disorder and is associated with considerable role impairment, especially in high-income countries, underscoring its public health significance.

veys in 26 countries are included in this report (Table 1 ). The surveys were fielded between 2001 and 2012 and had a weighted mean response rate of $69.5 \%$ (eTable 1 in the Supplement). All surveys included nationally or regionally representative samples of the household population. Sampling and weighting methods are detailed elsewhere. ${ }^{15}$ To summarize results across surveys, we used World Bank criteria ${ }^{16}$ to classify surveys into 3 country-level income groups: (1) low income and lower-middle income, (2) upper-middle income, and (3) high income. We refer to these groups as low, middle, and high income for ease of presentation.

All surveys used the WHO Composite International Diagnostic Interview (CIDI), ${ }^{17}$ a validated, fully structured, layadministered interview. Prior to administration in each country, the CIDI was translated, back-translated, and harmonized using standardized procedures. ${ }^{18}$ Consistent training and field quality control procedures were established across countries. ${ }^{19}$ Interviews were administered face-to-face in 2 parts. Part 1 , which assessed a core set of mental disorders including GAD, was administered to all respondents. Part 2, which assessed additional disorders, was administered to respondents with a part 1 disorder plus a probability subsample of other respondents. Comorbidity analyses were performed using the part 2 sample, which was weighted to adjust for differential probability of selection into part 2 . All other analyses used the part 1 sample. A human subjects review board or ethics committee approved the survey protocol in each country (eAppendix in the Supplement), and all respondents gave informed consent; the mode of consent (written vs oral) varied by survey. The presence and type of compensation also varied among surveys. ${ }^{19}$

\section{Measures}

\section{Generalized Anxiety Disorder}

The CIDI was used to assess lifetime, 12-month, and 30-day GAD. In the US survey, lifetime GAD diagnoses based on the CIDI had good concordance ${ }^{20}$ with diagnoses based on the clinician-administered Structured Clinical Interview for $D S M-I V$ (SCID). ${ }^{21}$ A clinical reappraisal study including other WMH surveys did not evaluate GAD in isolation but found good concordance between CIDI and SCID diagnoses of any 12 -month anxiety disorder, including GAD. ${ }^{22}$ Following the 


\begin{tabular}{|c|c|c|c|c|c|}
\hline \multirow[b]{2}{*}{ Country } & \multicolumn{4}{|c|}{ Prevalence, No. (\%) $[S E]^{a}$} & \multirow[b]{2}{*}{$\begin{array}{l}\text { Total } \\
\text { Sample, } \\
\text { No. }\end{array}$} \\
\hline & $\begin{array}{l}\text { Lifetime } \\
\text { Prevalence }\end{array}$ & $\begin{array}{l}\text { 12-mo } \\
\text { Prevalence }\end{array}$ & $\begin{array}{l}30-\mathrm{d} \\
\text { Prevalence }\end{array}$ & $\begin{array}{l}\text { 12-mo Prevalence } \\
\text { Among Lifetime } \\
\text { Cases }\end{array}$ & \\
\hline Low income & $596(1.6)[0.1]$ & $345(0.9)[0.1]$ & $186(0.5)[0.1]$ & $345(59.5)[2.4]$ & 36498 \\
\hline Colombia & $84(1.9)[0.3]$ & $39(1.0)[0.2]$ & $17(0.4)[0.1]$ & 39 (53.8) [7.7] & 4426 \\
\hline Iraq & $220(5.0)[0.6]$ & $131(3.0)[0.4]$ & $82(2.0)[0.3]$ & $131(61.3)[4.4]$ & 4332 \\
\hline Nigeria & $8(0.1)[0]$ & $1(0.0)[0]$ & 0 & $1(32.9)[24.0]$ & 6752 \\
\hline Peru & $40(1.1)[0.1]$ & $17(0.5)[0.1]$ & $2(0.1)[0]$ & $17(44.2)$ [6.7] & 3930 \\
\hline PRC Beijing/Shanghai & $60(1.0)[0.1]$ & $36(0.6)[0.1]$ & $15(0.3)[0.1]$ & $36(61.1)[7.1]$ & 5201 \\
\hline PRC Shenzhen & $19(0.2)[0.1]$ & $14(0.1)[0.1]$ & 0 & $14(76.9)[11.3]$ & 7132 \\
\hline Ukraine & $165(3.3)[0.3]$ & $107(2.1)[0.2]$ & $70(1.3)[0.1]$ & $107(63.1)[3.7]$ & 4725 \\
\hline Middle income & $875(2.8)[0.1]$ & $507(1.6)[0.1]$ & $231(0.7)[0.1]$ & $507(56.1)[2.1]$ & 28927 \\
\hline Brazil & $280(5.1)[0.4]$ & $187(3.3)[0.3]$ & $100(1.8)[0.2]$ & $187(63.4)[3.8]$ & 5037 \\
\hline Bulgaria & $125(2.3)[0.2]$ & $57(1.2)[0.1]$ & $23(0.5)[0.1]$ & $57(49.5)[4.8]$ & 5318 \\
\hline Colombia (Medellín) & $127(3.8)[0.5]$ & $73(2.1)[0.3]$ & $31(0.9)[0.2]$ & $73(56.2)[5.6]$ & 3261 \\
\hline Lebanon & $71(2.3)[0.3]$ & $47(1.5)[0.3]$ & $22(0.6)[0.2]$ & $47(64.5)[7.5]$ & 2857 \\
\hline Mexico & $78(1.1)[0.2]$ & $44(0.6)[0.1]$ & $19(0.3)[0.1]$ & $44(48.8)[7.7]$ & 5782 \\
\hline Romania & $27(1.0)[0.3]$ & $9(0.2)[0.1]$ & $8(0.2)[0.1]$ & 9 (24.5) [8.9] & 2357 \\
\hline South Africa & $167(3.6)[0.4]$ & $90(1.9)[0.3]$ & $28(0.6)[0.1]$ & $90(53.5)[4.8]$ & 4315 \\
\hline High income & $4417(5.0)[0.1]$ & $2031(2.3)[0.1]$ & $850(0.9)[0]$ & 2031 (45.9) [0.9] & 81836 \\
\hline Australia & $710(8.0)[0.5]$ & $312(3.6)[0.3]$ & $128(1.5)[0.2]$ & $312(45.4)[2.7]$ & 8460 \\
\hline Belgium & $75(2.8)[0.5]$ & $27(0.9)[0.3]$ & $10(0.3)[0.1]$ & $27(31.2)[7.1]$ & 2419 \\
\hline France & $190(6.2)[0.5]$ & $61(2.1)[0.3]$ & $20(0.6)[0.2]$ & $61(33.7)[3.7]$ & 2894 \\
\hline Germany & $58(1.5)[0.2]$ & $22(0.5)[0.1]$ & $6(0.2)[0.1]$ & $22(34.8)[7.5]$ & 3555 \\
\hline Israel & $216(4.4)[0.3]$ & $148(3.1)[0.3]$ & $50(1.1)[0.2]$ & $148(70.7)[3.1]$ & 4859 \\
\hline Italy & $100(2.1)[0.3]$ & $28(0.6)[0.1]$ & $9(0.2)[0.1]$ & $28(28.4)[5.2]$ & 4712 \\
\hline Japan & $105(2.6)[0.3]$ & $53(1.2)[0.2]$ & $8(0.2)[0.1]$ & $53(47.6)[5.0]$ & 4129 \\
\hline New Zealand & $1084(7.9)[0.3]$ & $441(3.1)[0.2]$ & $187(1.2)[0.1]$ & $441(38.5)[2.0]$ & 12790 \\
\hline Northern Ireland & $334(6.4)[0.4]$ & $150(2.8)[0.3]$ & $82(1.5)[0.2]$ & $150(44.2)[3.2]$ & 4340 \\
\hline Poland & $90(0.9)[0.1]$ & $52(0.5)[0.1]$ & $25(0.3)[0.1]$ & $52(58.4)[5.1]$ & 10081 \\
\hline Portugal & $269(6.1)[0.5]$ & 145 (3.3) [0.3] & $45(1.1)[0.2]$ & $145(53.0)[3.2]$ & 3849 \\
\hline Spain & $131(1.9)[0.2]$ & $59(0.8)[0.2]$ & $33(0.4)[0.1]$ & 59 (43.8) [6.3] & 5473 \\
\hline Spain (Murcia) & $193(7.0)[0.9]$ & $111(4.3)[0.7]$ & $77(3.0)[0.6]$ & $111(61.3)[3.3]$ & 2621 \\
\hline The Netherlands & $110(3.6)[0.4]$ & $28(1.0)[0.2]$ & $13(0.4)[0.1]$ & $28(28.2)[5.8]$ & 2372 \\
\hline United States & $752(7.8)[0.3]$ & $394(4.0)[0.2]$ & $157(1.6)[0.2]$ & $394(52.1)$ [1.8] & 9282 \\
\hline All countries & $5888(3.7)[0.1]$ & $2883(1.8)[0.1]$ & $1267(0.8)[0]$ & $2883(48.8)[0.8]$ & 147261 \\
\hline $\begin{array}{l}\text { Comparison between } \\
\text { individual countries }\end{array}$ & 85.8 & 42.7 & 29.0 & 6.7 & \\
\hline $\begin{array}{l}\text { Comparison between } \\
\text { country income groups }\end{array}$ & 311.3 & 106.5 & 21.7 & 20.4 & \\
\hline
\end{tabular}

Abbreviation: PRC, People's Republic of China.

a The ratio of numerator to denominator numbers does not equal the reported percentages because the percentages are weighted.

${ }^{\mathrm{b}} \chi_{28}^{2}$ Test of homogeneity for variation in prevalence estimates across countries; all $P<.001$.

${ }^{c} \chi_{2}^{2}$ Test of homogeneity for variation in prevalence estimates across low-, middle-, and high-income countries; all $P<.001$. lead of prior studies that modified the CIDI GAD algorithm to evaluate specific diagnostic changes, ${ }^{20,23,24}$ we generated $D S M-5$ GAD diagnoses by removing the DSM-IV hierarchical exclusion of a GAD diagnosis when symptoms occur exclusively during a mood disorder. ${ }^{25}$ Age of onset (AOO) of GAD was assessed using probing methods that have been demonstrated to improve dating accuracy. ${ }^{26}$ Persistence of GAD was estimated indirectly by calculating the proportion of respondents with 12-month GAD among those with the lifetime disorder.

\section{Impairment}

Respondents with 12-month GAD were administered an expanded version of the Sheehan Disability Scale ${ }^{27}$ to assess role impairments caused by the disorder during the worst month in the year before the interview. Respondents rated the extent of interference with home management, work, close relationships, and social life on separate 0-to-10 scales. We grouped ratings into categories of absent (0), mild (1-3), moderate (4-6), and severe (7-10) impairment for analysis. We also assessed the number of days in the past 12 months during which respondents reported being totally unable to work or carry out usual activities because of GAD.

\section{Comorbid Disorders}

Mental disorders other than GAD were diagnosed using DSM-IV criteria. They included other anxiety disorders (ie, panic disorder, agoraphobia, social phobia, specific phobia, posttrau- 
matic stress disorder, and separation anxiety disorder with onset either in childhood or adulthood), mood disorders (ie, major depression and bipolar spectrum disorder ${ }^{28}$ ), disruptive behavior disorders (ie, oppositional defiant disorder, conduct disorder, intermittent explosive disorder, attention-deficit/ hyperactivity disorder, bulimia nervosa, and binge eating disorder), and substance-related disorders (ie, alcohol and drug abuse and dependence).

\section{Other Measures}

Sociodemographic variables included respondent age, sex, marital status, educational level, household income (stratified into quartiles within country), and employment status at the time of the interview. Treatment seeking was assessed by asking whether respondents received treatment for any mental health or substance-related problem during the past 12 months. Treatment in 4 sectors was probed: specialty mental health, general medical health, human services, and complementary-alternative medicine.

\section{Statistical Analysis}

Cross-tabulations were used to estimate prevalence, comorbidity, impairment, and treatment. Logistic regression and survival analysis were used to examine sociodemographic correlates. The actuarial method ${ }^{29}$ was used to generate AOO survival curves. Design-based SEs were estimated using the Taylor series linearization method ${ }^{30}$ implemented in SUDAAN version $11.0^{31}$ to adjust for data weighting and clustering. Statistical significance was evaluated using Wald and McNemar $\chi^{2}$ tests. All tests were 2 -sided and used a significance threshold of $P<.05$. Data analysis was performed from July 22, 2015, to December 12, 2016.

\section{Results}

Prevalence

Across all surveys, the combined lifetime prevalence of GAD was $3.7 \%, 12$-month prevalence was $1.8 \%$, and 30 -day prevalence was $0.8 \%$ (Table 1 ). Lifetime prevalence estimates varied widely across countries, ranging from less than $1 \%$ of the populations of Nigeria and Shenzhen, China, to approximately $8 \%$ of the populations of Australia, New Zealand, and the United States. Prevalence increased with economic development: lifetime estimates (SE) were lowest in low-income $(1.6 \%$ [0.1\%]), moderate in middle-income (2.8\% [0.1\%]), and highest in high-income (5.0\% [0.1\%]) countries.

\section{Sociodemographic Correlates}

Around the world, being female, younger than 60 years, and unmarried (previously married or never married) were associated with GAD (eTable 2 in the Supplement). In addition, GAD was found disproportionately in respondents with lower educational levels, lower household income, and Other employment status (mostly unemployed or disabled). These correlates were relatively modest in magnitude (odds ratio [OR], 1.1; 95\% CI, 1.0-1.3 to OR, 1.8; 95\% CI, 1.7-2.0) except for the mark- edly increased odds of GAD among younger cohorts (OR, 3.0; 95\% CI, 2.7-3.3 to OR, 6.0; 95\% CI, 5.1-7.0). The pattern of correlates was similar across country groups, although GAD was associated less consistently with educational level, household income, and employment status in middle- and lowincome countries.

\section{Onset and Course}

Generalized anxiety disorder typically begins in adulthood (eFigure in the Supplement). Onset before puberty was rare in these surveys, with only $5 \%$ of cases developing by age 13 years. There was a gradual, steady accumulation of new cases over the lifespan, with $25 \%$ of all cases emerging by 25 years, $50 \%$ of the cases emerging by 39 years, and $75 \%$ of the cases emerging by 53 years. Although the AOO distribution was shifted earlier for high-income countries (median AOO, 36 years) relative to middle- and low-income countries (median AOO, 43 years for both), the distributions were substantively similar across country groups $\left(\chi_{2}^{2}=1.9\right.$, $P=.38)$.

Consistent with conceptualizations of GAD as a chronic disorder, nearly half of all lifetime cases still had the disorder in the 12 months before the interview (Table 1). Generalized anxiety disorder was more persistent in low-income (59.5\%) and middle-income (56.1\%) countries than in high-income countries (45.9\%). Around the world, persistence was higher for earlier-onset GAD cases, for individuals with lower educational levels and family income, and for those not employed outside the home (ie, Other status, homemaker) (eTable 2 in the Supplement).

\section{Comorbidity}

Most individuals with lifetime (81.9\% [0.7\%]) and 12-month (70.8\% [1.2\%]) GAD had 1 or more comorbid DSM-IV/CIDI disorders (Table 2). The odds were highest for lifetime mood and anxiety disorders, lower for disruptive behavior disorders, and lowest for substance-related disorders. The single most common comorbid condition was major depressive disorder, which was found in $52.6 \%$ (0.9\%) of lifetime cases and $40.9 \%$ (1.3\%) of 12-month cases of GAD worldwide.

\section{Role Impairment}

Respondents with 12-month GAD reported a mean (SE) of 41.2 days (2.4) out of role due to GAD in the past year. Half (50.6\%) of the 12-month cases reported severe functional impairment resulting from GAD (Table 3). The rate of severe impairment was lower yet still substantial (35.3\%) among individuals with GAD who had no comorbid disorders (eTable 3 in the Supplement).

The proportion of participants with severe GAD-related impairment was highest in high-income (54.5\%), lower in middle-income (42.6\%), and lowest in low-income (39.0\%) countries. Generalized anxiety disorder was a more disabling disorder in some countries than others, with severe impairment reported by a small minority of persons with GAD in China (17.3\% in Shenzhen, $21.8 \%$ in Beijing/Shanghai) and Mexico $(28.7 \%)$ but by a large majority of those with GAD in the Netherlands (80.3\%) and Romania (82.3\%). Neverthe- 


\begin{tabular}{|c|c|c|c|c|}
\hline \multirow[b]{2}{*}{ DSM-IV Disorder } & \multicolumn{2}{|l|}{ Lifetime GAD } & \multicolumn{2}{|l|}{ 12-mo GAD } \\
\hline & No. (\%) $[S E]^{b}$ & OR $(95 \% \mathrm{CI})^{\mathrm{c}}$ & No. (\%) $[S E]^{d}$ & OR $(95 \% \mathrm{Cl})^{\mathrm{e}}$ \\
\hline \multicolumn{5}{|l|}{ Anxiety disorder } \\
\hline Panic disorder & $699(12.3)[0.7]$ & $9.8(8.6-11.2)$ & $328(11.8)[0.9]$ & $15.8(13.3-18.8)$ \\
\hline Agoraphobia & $506(9.4)[0.5]$ & $7.0(6.1-8.0)$ & $246(9.0)[0.7]$ & $11.3(9.3-13.7)$ \\
\hline Social phobia & $1303(26.1)[0.9]$ & $9.2(8.4-10.2)$ & $561(22.6)[1.2]$ & $12.3(10.7-14.0)$ \\
\hline Specific phobia & $1171(25.6)[0.8]$ & $4.4(4.0-4.8)$ & $546(25.2)[1.2]$ & $5.6(4.9-6.4)$ \\
\hline Posttraumatic stress disorder & $1208(21.0)[0.7]$ & $9.2(8.4-10.2)$ & $415(14.4)[0.8]$ & $10.8(9.4-12.4)$ \\
\hline Childhood-onset separation anxiety disorder ${ }^{f}$ & $201(8.6)[0.7]$ & $4.9(4.0-6.0)$ & & \\
\hline Adult-onset separation anxiety disorder & $390(15.5)[0.8]$ & $6.1(5.3-7.1)$ & $94(6.9)[0.8]$ & $8.2(6.2-10.7)$ \\
\hline Any anxiety disorder & $2929(51.7)[0.9]$ & $8.0(7.4-8.7)$ & $1257(44.0)[1.2]$ & $9.3(8.5-10.3)$ \\
\hline \multicolumn{5}{|l|}{ Mood disorder } \\
\hline Major depressive disorder & $3055(52.6)[0.9]$ & $10.6(9.7-11.4)$ & $1173(40.9)[1.3]$ & $16.3(14.6-18.2)$ \\
\hline Bipolar spectrum disorder ${ }^{g}$ & $544(11.4)[0.6]$ & $7.6(6.7-8.7)$ & $267(10.8)[0.8]$ & $11.5(9.6-13.8)$ \\
\hline Any mood disorder ${ }^{h}$ & $3657(63.0)[0.9]$ & $13.4(12.3-14.4)$ & $1467(51.1)[1.3]$ & $19.6(17.6-21.8)$ \\
\hline \multicolumn{5}{|l|}{ Disruptive behavior disorder } \\
\hline Oppositional defiant disorder & $190(10.7)[0.9]$ & $4.4(3.5-5.4)$ & $34(3.5)[0.7]$ & $8.9(5.5-14.2)$ \\
\hline Conduct disorder & $142(7.8)[0.8]$ & $4.3(3.4-5.4)$ & $11(1.0)[0.3]$ & $3.6(1.8-7.2)$ \\
\hline Intermittent explosive disorder & $342(15.0)[1.1]$ & $5.7(4.7-6.8)$ & $149(12.1)[1.4]$ & $7.1(5.5-9.3)$ \\
\hline Attention-deficit/hyperactivity disorder & $158(7.5)[0.8]$ & $4.6(3.7-5.8)$ & $68(5.8)[0.9]$ & $8.3(6.0-11.5)$ \\
\hline Bulimia nervosa & $115(3.8)[0.4]$ & $5.8(4.5-7.5)$ & $33(2.4)[0.5]$ & $9.5(6.0-15.1)$ \\
\hline Binge eating disorder & $150(6.1)[0.6]$ & $4.4(3.5-5.5)$ & $53(4.3)[0.8]$ & $6.8(4.6-10.1)$ \\
\hline Any disruptive behavior disorder & $566(10.1)[0.6]$ & $4.0(3.5-4.4)$ & $122(8.1)[0.8]$ & $6.2(5.2-7.4)$ \\
\hline \multicolumn{5}{|l|}{ Substance-related disorder } \\
\hline Alcohol abuse & $1004(19.6)[0.8]$ & $2.5(2.2-2.7)$ & $149(5.8)[0.6]$ & $2.9(2.3-2.6)$ \\
\hline Alcohol dependence & $490(8.9)[0.5]$ & $4.6(3.9-5.3)$ & $106(4.4)[0.6]$ & $6.0(4.5-8.1)$ \\
\hline Drug abuse & $459(10.5)[0.6]$ & $3.9(3.4-4.5)$ & $71(3.6)[0.6]$ & $6.9(4.8-9.8)$ \\
\hline Drug dependence & $245(5.3)[0.4]$ & $5.9(4.8-7.2)$ & $52(2.5)[0.5]$ & $10.5(6.8-16.2)$ \\
\hline Any substance-related disorder & $1141(22.5)[0.8]$ & $2.7(2.5-3.0)$ & $221(9.1)[0.8]$ & $3.9(3.2-4.7)$ \\
\hline Any mental disorder & $4627(81.9)[0.7]$ & $12.3(11.2-13.6)$ & $1998(70.8)[1.2]$ & $14.9(13.2-16.7)$ \\
\hline \multicolumn{2}{|c|}{ Abbreviations: GAD, generalized anxiety disorder; OR, odds ratio. } & \multicolumn{3}{|c|}{ the 12-month DSM-IV disorder in each row. } \\
\hline \multicolumn{2}{|c|}{$\begin{array}{l}\text { a The ratio of numerator to denominator numbers does not equal the reported } \\
\text { percentages because the percentages are weighted. }\end{array}$} & \multicolumn{3}{|c|}{$\begin{array}{l}\text { e Based on separate logistic regression models using } 12 \text {-month GAD to predict } \\
\text { each } 12 \text {-month comorbid disorder; all significant at } P<.001 \text {. }\end{array}$} \\
\hline \multicolumn{2}{|c|}{$\begin{array}{l}\text { b Proportion of respondents with lifetime DSM-5 GAD who also qualified for the } \\
\text { lifetime DSM-IV disorder in each row. }\end{array}$} & \multicolumn{3}{|c|}{$\begin{array}{l}\text { f The surveys did not include a 12-month assessment of childhood-onset } \\
\text { separation anxiety disorder. }\end{array}$} \\
\hline \multicolumn{2}{|c|}{$\begin{array}{l}\text { ' Based on separate logistic regression models using lifetime GAD to predict } \\
\text { each lifetime comorbid disorder; all significant at } P<.001 \text {. }\end{array}$} & \multicolumn{3}{|c|}{$\begin{array}{l}{ }^{\mathrm{g}} \text { Includes bipolar I disorder, bipolar II disorder, or subthreshold bipolar disorder } \\
\text { as defined by Merikangas et al. }{ }^{28}\end{array}$} \\
\hline \multicolumn{2}{|c|}{${ }^{\mathrm{d}}$ Proportion of respondents with 12 -month DSM-5 GAD who also qualified for } & \multicolumn{3}{|c|}{ h Includes major depressive episode and bipolar spectrum disorder. } \\
\hline
\end{tabular}

less, the proportion of severely impaired persons was sizable in most countries (median, $48.6 \%$; interquartile range, $39.4 \%-56.2 \%)$.

\section{Treatment}

Approximately half (49.2\%) of respondents with 12-month GAD reported receiving some form of mental health treatment during the previous year (Table 4). Treatment was sought disproportionately by those with comorbid disorders $(55.8 \%)$ but was also sought by approximately one-third (32.4\%) of respondents with GAD alone (eTable 4 in the Supplement). The treatment rate was higher in high-income (59.0\%) than in middleincome $(29.1 \%)$ or low-income $(21.7 \%)$ countries. However, across countries, the overall pattern was of increasing use of services, particularly specialty mental health services, with increasing impairment due to GAD.

\section{Discussion}

The present findings shed new light on patterns of GAD around the globe. First, we showed that diagnostic changes from $D S M-I V$ to DSM-5 yielded an influx of new GAD cases, as lifetime prevalence estimates reported herein are $37 \%$ to $90 \%$ higher than published estimates for DSM-IV GAD in the United States. ${ }^{32,33}$ In the current WMH surveys, lifetime prevalence is $37 \%$ higher and 12 -month prevalence is $50 \%$ higher for DSM-5 than DSM-IV GAD (Ruscio AM, Hallion LS, Demyttenaere K, Lee S, Lim CCW. Generalized anxiety disorder. In: Scott KM, de Jonge P, Stein DJ, Kessler RC, eds. The Cross-National Epidemiology of Mental Disorders: Facts and Figures From the World Mental Health Surveys. Cambridge, England: Cambridge University Press; in press). Although an increase in prevalence was 


\begin{tabular}{|c|c|c|c|c|c|c|}
\hline \multirow[b]{2}{*}{ Country Income } & \multicolumn{5}{|c|}{ Proportion With Severe Role Impairment, No. (\%) [SE] $]^{\mathrm{a}, \mathrm{b}}$} & \multirow{2}{*}{$\begin{array}{l}\text { Sample } \\
\text { Size, No. }\end{array}$} \\
\hline & Home & Work & Relationship & Social & Anyc & \\
\hline Low income & 79 (23.2) [2.8] & $74(23.7)$ [3.3] & 79 (26.1) [3.4] & $67(24.6)$ [3.7] & $126(39.0)[3.6]$ & 345 \\
\hline Middle income & $120(25.8)[2.2]$ & $24(28.7)[3.0]$ & $123(26.8)[2.2]$ & $128(28.4)[2.8]$ & $192(42.6)[3.0]$ & 507 \\
\hline High income & $565(29.4)[1.3]$ & $625(34.4)$ [1.4] & $628(33.0)[1.3]$ & $712(38.1)$ [1.4] & 1049 (54.5) [1.4] & 2031 \\
\hline All countries & $764(28.0)[1.1]$ & $816(32.1)$ [1.2] & 830 (31.1) [1.1] & 907 (34.9) [1.2] & $1367(50.6)$ [1.2] & 2883 \\
\hline $\begin{array}{l}\text { Comparison between } \\
\text { countries }^{d}\end{array}$ & $\begin{array}{l}2.5 \\
(P=.08)\end{array}$ & $\begin{array}{l}5.4 \\
(P=.004)\end{array}$ & $\begin{array}{l}4.1 \\
(P=.02)\end{array}$ & $\begin{array}{l}9.6 \\
(P<.001)\end{array}$ & $\begin{array}{l}13.0 \\
(P<.001)\end{array}$ & \\
\hline \multicolumn{7}{|c|}{$\begin{array}{l}\text { a The ratio of numerator to denominator numbers does not equal the reported } \\
\text { percentages because the percentages are weighted. }\end{array}$} \\
\hline \multicolumn{3}{|c|}{$\begin{array}{l}\text { b Sheehan Disability Scale scores for severe impairment range from } 7 \text { to } 10 . \\
\text { Respondents rated the extent of interference with home management, work, } \\
\text { close relationships, and social life on separate 0-to-10 scales and were } \\
\text { assigned to a severity category based on their highest impairment rating }\end{array}$} & \multicolumn{4}{|c|}{$\begin{array}{l}\text { c Proportion with severe role impairment in at least } 1 \text { of the } 4 \text { Sheehan Disability } \\
\text { Scale role domains. } \\
{ }^{d} \chi_{2}^{2} \text { Test of homogeneity for variation in impairment severity across low-, } \\
\text { middle-, and high-income countries. }\end{array}$} \\
\hline
\end{tabular}

expected, these estimates reveal that the increase was substantial. The newly identified individuals, who previously were barred from a GAD diagnosis by a concomitant mood disorder, have been shown in outpatient samples to experience a particularly severe form of GAD with a high burden of comorbidity. ${ }^{34,35}$ Consistent with this account, we found that more than $80 \%$ of people with lifetime GAD experienced another lifetime disorder, most often major depressive disorder. Given the frequent occurrence of GAD during mood episodes and the implications of comorbidity for treatment, ${ }^{36}$ these findings underscore the importance of systematic assessment and appropriate management of GAD in patients with mood disorders.

Second, the prevalence of GAD varied widely across countries, with rates generally higher in higher-income countries. This means that the global prevalence of GAD may be considerably lower than the previous best-estimate rates of $6.2 \%$ (lifetime) and 2.6\% (12-month), which were based exclusively on high-income countries. ${ }^{37}$ This finding aligns with the broader pattern of higher rates of psychopathology in wealthier countries $^{38}$ that has variously been attributed to methodologic artifacts, differential reporting of mental illness, or differences in risk and protective factors across countries. ${ }^{39-41} \mathrm{~A}$ further possibility specific to GAD is that cognitive symptoms of the disorder may be reported less frequently than somatic symptoms in developing countries, ${ }^{42,43}$ implying that clinically significant anxiety in those countries may be missed by the DSM-5 emphasis on worry. Another possibility is that, when worry is reported, it may focus on a single dominant concern (eg, financial worry) ${ }^{44}$ or fail to be judged as excessive owing to genuinely difficult life circumstances. ${ }^{45} \mathrm{~A}$ simple form of this explanation is contradicted by higher rates of GAD in persons of lower socioeconomic status who presumably have the most stress and fewest resources. A more nuanced form is that individual differences in the propensity to worry may be more evident under conditions of relative wealth and stability, such as those found in high-income countries, than under conditions of relative scarcity and instability, where worry may be expected and widespread.

The prevalence of DSM-5 GAD was concentrated among individuals who were female, younger than 60 years, unmarried, not employed, less educated, and less affluent relative to national standards. Contrary to most mental disorders, ${ }^{46}$ onset of GAD before adulthood was uncommon, occurring in fewer than $25 \%$ of the cases. Instead, new cases accrued gradually from puberty through 65 years. These findings are consistent with previous epidemiologic studies in high-income countries $^{32,47}$ and suggest that onset or recognition of the disorder is even later in lower-income countries. The relatively shallow AOO distribution seems unlikely to result from retrospective recall biases, as surveys of adolescents have yielded similar findings. ${ }^{48,49}$ A more plausible explanation is that GAD may be triggered by stressful life events at any time in the lifespan, ${ }^{50,51}$ accounting for the gradual accumulation of cases. Another possibility is that a temperamental predisposition to worry, emerging early in life, does not cause marked distress or impairment until a significant stressor-or chronic stress of the sort associated with the socioeconomic profile characteristic of GAD-overwhelms the individual's capacity to keep worry in check. ${ }^{52,53}$ Once GAD begins, it often persists: nearly half of the individuals with lifetime GAD met 12-month criteria for the disorder. However, persistence varied widely, with higher persistence reported in lower-income countries. Taken together, these findings provide mixed support for conventional views of GAD as a chronic condition present since early life. ${ }^{54-57}$ Instead, we found that the GAD syndrome usually first emerges in adulthood and that its course, although often unremitting, differs substantially by country.

Contrary to some characterizations of GAD as a disease of the "worried well," 1,6 GAD was associated with marked disability. Half of the individuals with 12-month GAD reported severe disability in 1 or more life domains resulting from the disorder. Moreover, individuals reported a mean of more than 40 days in the past year when they were completely unable to work or carry out daily activities because of GAD. Finally, GAD was associated with significant help seeking, with approximately half of the individuals with 12 -month GAD receiving treatment during the past year. Consistent with conceptions of comorbidity as a severity marker, ${ }^{58}$ individuals whose GAD occurred with other disorders reported greater disability due to $\mathrm{GAD}$ and greater use of mental health services. However, even in the absence of other disorders, one-third of individuals with GAD reported severe impairment and treatment. These results extend prior findings of general health-related disabil- 


\begin{tabular}{|c|c|c|c|c|}
\hline \multirow[b]{3}{*}{ Treatment Sector } & \multicolumn{4}{|c|}{ Proportion Who Received Mental Health Treatment in the Past $12 \mathrm{mo}$, No. (\%) [SE] } \\
\hline & \multirow[b]{2}{*}{ All 12-mo GAD Cases } & \multicolumn{3}{|c|}{ Severity of Role Impairment ${ }^{b}$} \\
\hline & & Mild & Moderate & Severe \\
\hline \multicolumn{5}{|l|}{ Specialty mental healthc } \\
\hline Low income & $14(3.7)[1.4]$ & & & $9(8.4)[3.8]$ \\
\hline Middle income & $80(16.5)[2.3]$ & & $17(13.2)[3.9]$ & $40(22.8)[4.2]$ \\
\hline High income & $632(32.3)[1.3]$ & $38(22.8)[4.7]$ & $128(23.0)[2.1]$ & $410(41.8)[2.0]$ \\
\hline All countries & $726(26.0)[1.1]$ & $42(18.1)[3.6]$ & $148(18.1)[1.6]$ & 459 (35.9) [1.7] \\
\hline Comparison between countries $^{d}$ & $\begin{array}{l}72.1 \\
(P<.001)\end{array}$ & & $\begin{array}{l}30.5 \\
(P<.001)\end{array}$ & $\begin{array}{l}23.4 \\
(P<.001)\end{array}$ \\
\hline \multicolumn{5}{|l|}{ General medical ${ }^{\mathrm{e}}$} \\
\hline Low income & $40(11.4)[2.2]$ & & $13(11.5)[3.3]$ & $20(16.0)[4.4]$ \\
\hline Middle income & $79(14.7)[2.0]$ & $11(21.2)[7.0]$ & $17(10.5)[2.7]$ & $30(15.9)[3.6]$ \\
\hline High income & $847(41.0)[1.4]$ & $64(36.7)[5.0]$ & $189(33.4)[2.4]$ & $496(46.7)[1.9]$ \\
\hline All countries & $966(32.8)[1.1]$ & $79(30.3)[3.9]$ & $219(26.2)[1.8]$ & $546(39.4)[1.7]$ \\
\hline Comparison between countries $^{d}$ & $\begin{array}{l}76.8 \\
(P<.001)\end{array}$ & $\begin{array}{l}6.4 \\
(P<.001)\end{array}$ & $\begin{array}{l}21.9 \\
(P<.001)\end{array}$ & $\begin{array}{l}35.2 \\
(P<.001)\end{array}$ \\
\hline \multicolumn{5}{|l|}{ Human services ${ }^{f}$} \\
\hline Low income & $17(6.4)[2.2]$ & & $6(10.1)[5.6]$ & $8(4.2)[1.2]$ \\
\hline Middle income & $19(3.8)[1.0]$ & & & $13(6.9)[2.4]$ \\
\hline High income & $152(7.6)[0.8]$ & $8(4.4)[1.6]$ & $30(4.9)[1.1]$ & $100(9.8)[1.2]$ \\
\hline All countries & $188(6.8)[0.6]$ & $12(4.7)[1.5]$ & $37(4.9)[1.1]$ & $121(8.9)[1.0]$ \\
\hline Comparison between countries $^{d}$ & $\begin{array}{l}4.7 \\
(P=.01)\end{array}$ & & $\begin{array}{l}8.8 \\
(P<.001)\end{array}$ & $\begin{array}{l}4.3 \\
(P=.01)\end{array}$ \\
\hline \multicolumn{5}{|l|}{ Complementary-alternative medicine ${ }^{g}$} \\
\hline Low income & $8(2.4)[0.9]$ & & & \\
\hline Middle income & $21(4.0)[1.5]$ & & & $12(7.3)[3.5]$ \\
\hline High income & $164(8.2)[0.8]$ & $7(3.4)[1.4]$ & $37(6.7)[1.3]$ & $111(11.6)[1.3]$ \\
\hline All countries & $193(6.8)[0.6]$ & $11(3.6)[1.2]$ & $43(5.1)[0.9]$ & $126(10.0)[1.1]$ \\
\hline Comparison between countries $^{d}$ & $\begin{array}{l}12.0 \\
(P<.001)\end{array}$ & & & $\begin{array}{l}9.9 \\
(P<.001)\end{array}$ \\
\hline \multicolumn{5}{|l|}{ Any treatment ${ }^{\mathrm{h}}$} \\
\hline Low income & $71(21.7)[3.3]$ & $7(15.9)[5.6]$ & $23(23.4)[6.4]$ & $35(27.4)[5.7]$ \\
\hline Middle income & $156(29.1)[2.8]$ & $15(30.0)[7.6]$ & $35(24.5)[4.8]$ & $70(35.9)[4.9]$ \\
\hline High income & $1205(59.0)[1.3]$ & $91(51.8)[4.9]$ & $275(48.7)[2.5]$ & $705(67.8)[1.9]$ \\
\hline All countries & $1432(49.2)[1.2]$ & $113(43.3)[4.0]$ & $333(40.7)[2.2]$ & $810(59.4)[1.8]$ \\
\hline Comparison between countries $^{d}$ & $\begin{array}{l}73.6 \\
(P<.001)\end{array}$ & $\begin{array}{l}7.2 \\
(P<.001)\end{array}$ & $\begin{array}{l}12.6 \\
(P<.001)\end{array}$ & $\begin{array}{l}28.7 \\
(P<.001)\end{array}$ \\
\hline
\end{tabular}

Abbreviation: GAD, generalized anxiety disorder

a Empty cells indicate fewer than 5 cases. The ratio of numerator to denominator numbers does not equal the reported percentages because the percentages are weighted.

${ }^{\mathrm{b}}$ Based on GAD-related impairment rated on the Sheehan Disability Scale. Sheehan Disability Scale scores were categorized as 1 to 3 (mild), 4 to 6 (moderate), and 7 to 10 (severe). Respondents rated the extent of interference with home management, work, close relationships, and social life on separate 0-to-10 scales and were assigned to a severity category based on their highest impairment rating across the 4 role domains.

c Includes psychiatrist, psychologist, or other mental health professional; social worker or counselor in a mental health specialty setting; use of a mental health helpline; or overnight admission for a mental health, drug, or alcohol problem, with a presumption of daily contact with a psychiatrist.

${ }^{d} \chi_{2}^{2}$ Test of homogeneity for variation in treatment estimates across low-, middle-, and high-income countries. The test was performed when more than 1 stable cell ( $\geq 5$ cases) was available for comparison.

e Includes general practitioner, other medical physician, nurse, occupational therapist, or other health care professional not previously mentioned.

${ }^{f}$ Includes religious or spiritual advisor, or social worker or counselor in any setting other than a specialty mental health setting.

$\mathrm{g}$ Includes any other type of healer, such as herbalist or homeopath; participation in an internet support group; or participation in a self-help group.

${ }^{\mathrm{h}}$ Respondents who sought any form of treatment listed above. ity and diminished quality of life in $\mathrm{GAD}^{59-61}$ by quantifying the impairment resulting from GAD in each life domain, showing that impairment is substantial in developing as well as developed countries, and describing the association between impairment and treatment seeking across countries.

Although GAD was impairing in all of the countries included in the present study, it was most impairing in high- income countries. This finding is particularly striking when contrasted against the greater frequency and persistence of GAD in individuals with lower socioeconomic status relative to national standards. The inverse associations with income at the individual vs national levels have been documented for many mental disorders and could reflect the influence of risk factors that vary with economic development. ${ }^{62}$ For ex- 
ample, greater industrialization and urbanization in higherincome countries may result in fewer community supports (eg, extended family and religious community) to buffer the impact of stressful events or assist with role functioning. In addition, there may be greater demands on individuals in higherincome countries to achieve independence, occupational success, and social status in a competitive environment, increasing uncertainty and perceived pressure to meet high expectations. ${ }^{63}$

\section{Limitations}

Our large general population sample offered unprecedented statistical power and the opportunity to study GAD in parts of the world in which, to our knowledge, no previous data were available. Nevertheless, the study was limited in several respects. Assessment was performed with fully structured interviews administered by lay interviewers. Clinical reappraisal studies have shown good concordance with the SCID but indicate that CIDI-based prevalence estimates tend to be conservative. ${ }^{22}$ Lifetime symptoms and disorder onset were reported retrospectively. Our measure of persistence could not distinguish chronic from recurrent cases and missed cases that resolved before the preceding 12 months. Finally, although the results varied systematically by country income strata, large differences in prevalence within strata suggest an influence of methodologic variation (eg, sample frames and/or response rates) or substantive factors (eg, sociocultural variables) not accounted for in our analyses.

\section{Conclusions}

Using data from 26 countries, we showed that DSM-5 GAD is a common disorder associated with considerable comorbidity and functional impairment. The disorder typically begins in adulthood, although its onset is later and its course is more persistent in less developed countries. Although GAD is found in similar subgroups within the countries examined, it is more prevalent and impairing in high-income than in lowor middle-income countries. Probing the mechanisms underlying these cross-national differences will advance understanding of GAD and inform debates regarding its validity and global relevance.

\section{ARTICLE INFORMATION}

Accepted for Publication: December 16, 2016.

Published Online: March 15, 2017. doi:10.1001/jamapsychiatry.2017.0056

Author Affiliations: Department of Psychology, University of Pennsylvania, Philadelphia (Ruscio); Department of Psychology, University of Pittsburgh, Pittsburgh, Pennsylvania (Hallion); Department of Psychological Medicine, University of Otago, Dunedin, Otago, New Zealand (Lim, Scott); Center for Reducing Health Disparities, University of California Davis Health System, Sacramento (Aguilar-Gaxiola); College of Medicine, Al-Qadisiya University, Diwania Governorate, Iraq (Al-Hamzawi); Health Services Research Unit, Institut Municipal d'Investigació Médica-Hospital del Mar Medical Research Institute, Barcelona, Spain (Alonso); Department of Experimental and Health Sciences, Pompeu Fabra University, Barcelona, Spain (Alonso); CIBER Epidemiología y Salud Pública (CIBERESP), Barcelona, Spain (Alonso); Department/Institute of Psychiatry, University of São Paulo Medical School, São Paulo, Brazil (Andrade); Calzada México Xochimilco No. 101 Delegación Tlalpan, Distrito Federal, Mexico (Borges); Department of Psychiatry, Stony Brook University School of Medicine, Stony Brook, New York (Bromet); School of Psychology, Ulster University, Londonderry, United Kingdom (Bunting); Chronic Diseases Research Center and Department of Mental Health, Faculdade de Ciências Médicas, Universidade Nova de Lisboa, Lisbon, Portugal (Caldas de Almeida); Department of Psychiatry, University Hospital Gasthuisberg, Katholieke Universiteit Leuven, Leuven, Belgium (Demyttenaere); National School of Public Health, Management and Professional Development, Bucharest, Romania (Florescu); Istituto Di Ricovero e Cura a Carattere Scientifico, St John of God Clinical Research Centre, Brescia, Italy (de Girolamo); Department of Psychiatry, University College Hospital, Ibadan, Nigeria (Gureje); Parc
Sanitari Sant Joan de Déu, Centro de Investigación Biomédica en Red Salud Mental, Universitat de Barcelona, Barcelona, Spain (Haro); Shanghai Mental Health Center, Shanghai, China $(\mathrm{He})$; National Center for Public Health and Analyses, Sofia, Bulgaria (Hinkov); Shenzhen Institute of Mental Health \& Shenzhen Kanging Hospital, Shenzhen, China (Hu); Developmental Psychology, Department of Psychology, Rijksuniversiteit Groningen, Groningen, the Netherlands (de Jonge); Interdisciplinary Center Psychopathology and Emotion Regulation, Department of Psychiatry, University Medical Center Groningen, Groningen, the Netherlands (de Jonge); Department of Psychiatry and Clinical Psychology, Faculty of Medicine, Balamand University, Beirut, Lebanon (Karam); Department of Psychiatry and Clinical Psychology, St George Hospital University Medical Center, Beirut, Lebanon (Karam); Institute for Development Research Advocacy and Applied Care, Beirut, Lebanon (Karam, Mneimneh); Department of Psychiatry, Chinese University of Hong Kong, Tai Po, Hong Kong (Lee); Hôpital Lariboisière Fernand Widal, Assistance Publique Hôpitaux de Paris, University Paris Diderot and Paris Descartes, Paris, France (Lepine); Ministry of Health Israel, Mental Health Services, Jerusalem, Israel (Levinson); Survey Research Center, Institute for Social Research, University of Michigan, Ann Arbor (Mneimneh); Unidad de Docencia, Investigación y Formación en Salud Mental, Subdirección General de Planificación, Innovación y Cronicidad, Servicio Murciano de Salud, Instituto Murciano de Investigación Biosanitaria-Arrixaca, Centro de Investigación Biomédica en Red Epidemiología y Salud Pública-Murcia, Murcia, Spain (Navarro-Mateu); Colegio Mayor de Cundinamarca University, Bogota, Colombia (Posada-Villa); National Drug and Alcohol Research Centre University of New South Wales, Sydney, Australia (Slade); Department of Psychiatry and Mental Health, University of Cape Town, Cape Town, Republic of South Africa (Stein); Center for
Excellence on Research in Mental Health, CES University, Medellín, Colombia (Torres); Health, Social Welfare, and Environmental Department, Kagoshima Regional Promotion Bureau, Kagoshima Prefecture, Japan (Uda); Centre of Monitoring and Analyses of Population Health, National Institute of Public Health-National Institute of Hygiene, Warsaw, Poland (Wojtyniak); Department of Health Care Policy, Harvard Medical School, Boston, Massachusetts (Kessler); Department of Information, Evidence and Research, World Health Organization, Geneva, Switzerland (Chatterji).

Author Contributions: Dr Scott had full access to all of the data in the study and takes responsibility for the integrity of the data and the accuracy of the data analysis.

Study concept and design: Ruscio, Kessler, Scott. Acquisition, analysis, or interpretation of data: All authors.

Drafting of the manuscript: Ruscio, Hallion. Critical revision of the manuscript for important intellectual content: All authors. Statistical analysis: Lim, Scott.

Obtained funding: Al-Hamzawi, Alonso, Andrade, Bromet, Bunting, Caldas de Almeida, Demyttenaere, Florescu, de Girolamo, Gureje, Haro, He, Hinkov, Hu, Karam, Lee, Lepine, Navarro-Mateu, Posada-Villa, Slade, Stein, Torres, Scott.

Supervision: Kessler, Scott.

Conflict of Interest Disclosures: Dr Demyttenaere reports grants from Eli Lilly, Foundation Ga voor Geluk, and the Flemish Research Fund. He has served as a consultant with Servier, Lundbeck, Lundbeck Institute, AstraZeneca, and Naurex. Dr Stein has received research grants and/or consultancy honoraria from Abbott, AstraZeneca, Eli Lilly and Company, GlaxoSmithKline, Jazz Pharmaceuticals, Johnson \& Johnson, Lundbeck, Orion, Pfizer, Pharmacia, Roche, Servier, Solvay, Sumitomo, Sun, Takeda, Tikvah, and Wyeth. Dr Kessler has received support for his epidemiologic studies from Sanofi, was a consultant 
for Johnson \& Johnson Wellness and Prevention, and served on an advisory board for the Johnson \& Johnson Services Inc Lake Nona Life Project. Dr Kessler is a co-owner of DataStat, Inc, a market research firm that carries out health care research. No other disclosures were reported.

Funding/Support: The WHO WMH Survey Initiative is supported by National Institute of Mental Health (NIMH) grant R01 MH070884; the John D. and Catherine T. MacArthur Foundation; the Pfizer Foundation; US Public Health Service grants R13-MH066849, R01-MH069864, and R01 DA016558; Fogarty International Center grant FIRCA R03-TW006481; the Pan American Health Organization; Eli Lilly and Company; Ortho-McNeil Pharmaceutical, Inc; GlaxoSmithKline; and Bristol-Myers Squibb. The 2007 Australian National Survey of Mental Health and Wellbeing is funded by the Australian Government Department of Health and Ageing. The São Paulo Megacity Mental Health Survey is supported by the State of São Paulo Research Foundation Thematic Project grant 03/ 00204-3. The Bulgarian Epidemiological Study of common mental disorders Epidemiology and Bulgaria is supported by the Ministry of Health and the National Center for Public Health Protection. The Chinese WMH Survey Initiative is supported by the Pfizer Foundation. The Shenzhen Mental Health Survey is supported by the Shenzhen Bureau of Health and the Shenzhen Bureau of Science, Technology, and Information. The Colombian National Study of Mental Health is supported by the Ministry of Social Protection. The Mental Health Study Medellín-Colombia was carried out and supported jointly by the Center for Excellence on Research in Mental Health (CES University) and the Secretary of Health of Medellín. The European Study of the Epidemiology of Mental Disorders project is funded by European Commission contracts QLG5-1999-01042, SANCO 2004123, and EAHC 20081308 (the Piedmont Region [Italy]); Fondo de Investigación Sanitaria; Instituto de Salud Carlos III, Spain grant FIS 00/0028; Ministerio de Ciencia y Tecnología, Spain, grant SAF 2000-158CE; Departament de Salut, Generalitat de Catalunya, Spain; Instituto de Salud Carlos III grants CIBER CB06/02/0046 and RETICS RD06/0011 REM-TAP; and other local agencies and by an unrestricted educational grant from

GlaxoSmithKline. Implementation of the Iraq Mental Health Survey (IMHS) and data entry were carried out by the staff of the Iraqi Ministry of Health and Ministry of Planning with direct support from the Iraqi IMHS team, with funding from both the Japanese and European Funds through United Nations Development Group Iraq Trust Fund. The Israel National Health Survey is funded by the Ministry of Health with support from the Israel National Institute for Health Policy and Health Services Research and the National Insurance Institute of Israel. The WMH Japan Survey is supported by grants H13-SHOGAI-O23, H14TOKUBETSU-026, and H16-KOKORO-013 for Research on Psychiatric and Neurological Diseases and Mental Health from the Japan Ministry of Health, Labour and Welfare. The Lebanese Evaluation of the Burden of Ailments and Needs of the Nation is supported by the Lebanese Ministry of Public Health, the WHO (Lebanon), National Institute of Health/Fogarty International Center grant R03 TW006481-01, anonymous private donations to Institute for Development Research Advocacy and Applied Care, Lebanon, and unrestricted grants from Algorithm, AstraZeneca, Benta, Bella Pharma, Eli Lilly, GlaxoSmithKline, Lundbeck, Novartis, Servier, Phenicia, and Union Pharmaceutique d'Orient SAL. The Mexican National Comorbidity Survey is supported by The National Institute of Psychiatry Ramon de la Fuente grant INPRFMDIES 4280 and by the National Council on Science and Technology grant CONACYT-G30544-H, with supplemental support from the Pan American Health Organization. Te Rau Hinengaro: The New Zealand Mental Health Survey is supported by the New Zealand Ministry of Health, Alcohol Advisory Council, and the Health Research Council. The Nigerian Survey of Mental Health and Wellbeing is supported by the WHO (Geneva), the WHO (Nigeria), and the Federal Ministry of Health, Abuja, Nigeria. The Northern Ireland Study of Mental Health was funded by the Health \& Social Care Research \& Development Division of the Public Health Agency. The Peruvian WMH Study was funded by the National Institute of Health of the Ministry of Health of Peru. The Polish project Epidemiology of Mental Health and Access to Care-EZOP Project grant PL 0256 was supported by Iceland, Liechtenstein, and Norway through funding from the European Economic Area Financial Mechanism and the Norwegian Financial Mechanism; the EZOP Project was cofinanced by the Polish Ministry of Health. The Portuguese Mental Health Study was carried out by the Department of Mental Health, Faculty of Medical Sciences, NOVA University of Lisbon, with collaboration of the Portuguese Catholic University. and was funded by Champalimaud Foundation, Gulbenkian Foundation, Foundation for Science and Technology and Ministry of Health. The Romania WMH Survey Initiative study projects Policies in Mental Health Area and National Study Regarding Mental Health and Services Use were carried out by the National School of Public Health \& Health Services Management (formerly the National Institute for Research \& Development in Health), with technical support of Metro Media Transilvania, the National Institute of Statistics-National Centre for Training in Statistics, Societatea Comerciala Cheyenne Services SRL, and Statistics Netherlands and were funded by the Ministry of Public Health (formerly the Ministry of Health) with supplemental support from Eli Lilly Romania SRL. The South Africa Stress and Health Study is supported by US NIMH grant RO1-MHO59575 and the National Institute of Drug Abuse, with supplemental funding from the South African Department of Health and the University of Michigan. The Psychiatric Enquiry to General Population in Southeast Spain-Murcia Project has been financed by the Regional Health Authorities of Murcia (Servicio Murciano de Salud and Consejería de Sanidad y Política Social) and Fundación para la Formación e Investigación Sanitarias of Murcia. The Ukraine Comorbid Mental Disorders During Periods of Social Disruption study is funded by US NIMH grant R01-MH61905. The US National Comorbidity Survey Replication is supported by NIMH grant U01-MH60220 with supplemental support from the National Institute of Drug Abuse, the Substance Abuse and Mental Health Services Administration, Robert Wood Johnson Foundation grant 044708, and the John W. Alden Trust. Preparation of this manuscript was supported by grant R01 MH094425 from the NIMH (Dr Ruscio).

Role of the Funder/Sponsor: The funding sources had no role in the design and conduct of the study; collection, management, analysis, and interpretation of the data; preparation, review, or approval of the manuscript; and decision to submit the manuscript for publication.

Disclaimer: The views and opinions expressed in this report are those of the authors and should not be construed to represent the views of the WHO or other sponsoring organizations, agencies, or governments.

Additional Information: The World Health Organization (WHO) World Mental Health (WMH) Survey Initiative collaborators are Sergio Aguilar-Gaxiola, MD, PhD (United States), Ali Al-Hamzawi, MD (Iraq), Mohammed Salih Al-Kaisy, MD (Iraq), Jordi Alonso, MD, PhD (Spain), Laura Helena Andrade, MD, PhD (Brazil), Corina Benjet, PhD (Mexico), Guilherme Borges, ScD (Mexico), Evelyn J. Bromet, PhD (United States), Ronny Bruffaerts, PhD (Belgium), Brendan Bunting, $\mathrm{PhD}$ (Northern Ireland), José Miguel Caldas de Almeida, MD, PhD (Portugal), Graca Cardoso, MD, PhD (Portugal), Somnath Chatterji, MD (Switzerland), Alfredo H. Cia, MD (Argentina), Louisa Degenhardt, PhD (Australia), Giovanni de Girolamo, MD (Italy), Peter de Jonge, PhD (the Netherlands), Koen Demyttenaere, MD, PhD (Belgium), John Fayyad, MD (Lebanon), Silvia Florescu, MD, PhD (Romania), Oye Gureje, MD, PhD, FRCPsych (Nigeria), Josep Maria Haro, MD, PhD (Spain), Yanling He, MD (China), Hristo Hinkov, MD, PhD (Bulgaria), Chiyi Hu, PhD, MD (China), Yueqin Huang, MD, MPH, PhD (China), Aimee Nasser Karam, PhD (Lebanon), Elie G. Karam, MD (Lebanon), Norito Kawakami, MD, DMSc (Japan), Ronald C. Kessler, PhD (United States), Andrzej Kiejna, MD, PhD (Poland), Viviane Kovess-Masfety, MD, PhD (France), Sing Lee, MB, BS (Hong Kong), Jean-Pierre Lepine, MD (France), Daphna Levinson, PhD (Israel), John McGrath, PhD (Australia), Maria Elena Medina-Mora, PhD (Mexico), Jacek Moskalewicz, DrPH (Poland), Fernando Navarro-Mateu, MD, PhD (Spain), Beth-Ellen Pennell, MA (United States), Marina Piazza, MPH, ScD (Peru), José Posada-Villa, MD (Colombia), Kate M. Scott, PhD (New Zealand), Tim Slade, PhD (Australia), Juan Carlos Stagnaro, MD, PhD (Argentina), Dan J. Stein, FRCPC, PhD (Republic of South Africa), Margreet ten Have, PhD (the Netherlands), Yolanda Torres, MPH (Colombia), Maria Carmen Viana, MD, PhD (Brazil), Harvey Whiteford, PhD (Australia), David R. Williams, MPH, $\mathrm{PhD}$ (Republic of South Africa), and Bogdan Wojtyniak, ScD (Poland). A complete list of all within-country and cross-national WMH Survey Initiative publications can be found at http://www .hcp.med.harvard.edu/wmh/.

Additional Contributions: We thank the staff of the WMH Data Collection and Data Analysis Coordination Centres for assistance with instrumentation, fieldwork, and consultation on data analysis. We thank Courtney Forbes, MEd (University of Pennsylvania) for assistance with manuscript preparation. There was no financial compensation.

\section{REFERENCES}

1. Dugas MJ, Anderson KG, Deschenes SS, Donegan E. Generalized anxiety disorder publications: where do we stand a decade later? J Anxiety Disord. 2010;24(7):780-784. 
2. Turk CL, Mennin DS. Phenomenology of generalized anxiety disorder. Psychiatr Ann. 2011;41 (2):72-78.

3. American Psychiatric Association. Diagnostic and Statistical Manual of Mental Disorders. 3rd ed. Washington, DC: American Psychiatric Association; 1980.

4. Rapee RM. Generalized anxiety disorder: a review of clinical features and theoretical concepts. Clin Psychol Rev. 1991;11(4):419-440.

5. Wittchen H-U, Essau CA, Krieg J-C. Anxiety disorders: similarities and differences of comorbidity in treated and untreated groups. $\mathrm{Br} \mathrm{J}$ Psychiatry Suppl. 1991;159(12):23-33.

6. Persons JB, Mennin DS, Tucker DE. Common misconceptions about the nature and treatment of generalized anxiety disorder. Psychiatr Ann. 2001; 31(8):501-507.

7. Ballenger JC, Davidson JR, Lecrubier Y, et al Consensus statement on generalized anxiety disorder from the International Consensus Group on Depression and Anxiety. J Clin Psychiatry. 2001; 62(11)(suppl 11):53-58.

8. Wittchen H-U, Kessler RC, Beesdo K, Krause P, Höfler M, Hoyer J. Generalized anxiety and depression in primary care: prevalence, recognition, and management. J Clin Psychiatry. 2002;63(8) (suppl 8):24-34.

9. Hudson CG. Socioeconomic status and menta illness: tests of the social causation and selection hypotheses. Am J Orthopsychiatry. 2005;75(1): 3-18.

10. Lorant V, Deliège D, Eaton W, Robert A, Philippot $P$, Ansseau M. Socioeconomic inequalities in depression: a meta-analysis. Am J Epidemiol. 2003;157(2):98-112.

11. Kleinman A. Culture and depression. NEngl J Med. 2004;351(10):951-953.

12. Ryder AG, Yang J, Zhu X, et al. The cultural shaping of depression: somatic symptoms in China, psychological symptoms in North America? J Abnorm Psychol. 2008;117(2):300-313.

13. Hopper K, Wanderling J; International Study of Schizophrenia. Revisiting the developed versus developing country distinction in course and outcome in schizophrenia: results from ISoS, the WHO collaborative followup project. Schizophr Bull. 2000:26(4):835-846

14. Kessler RC, Üstün TB, eds. The WHO World Mental Health Surveys: Global Perspectives on the Epidemiology of Mental Disorder. Cambridge, England: Cambridge University Press; 2008.

15. Heeringa SG, Wells JE, Hubbard F, et al. Sample designs and sampling procedures. In: Kessler RC, Üstün TB, eds. The WHO World Mental Health Surveys: Global Perspectives on the Epidemiology of Mental Disorder. Cambridge, England: Cambridge University Press; 2008:14-32

16. World Bank Country and Lending Groups. http: //go.worldbank.org/D7SNOB8YUO. Updated 2017. Accessed February 23, 2017.

17. Kessler RC, Ustün TB. The World Mental Health (WMH) Survey Initiative Version of the World Health Organization (WHO) Composite International Diagnostic Interview (CIDI). Int J Methods Psychiatr Res. 2004;13(2):93-121.

18. Harkness J, Pennell BE, Villar A, Gebler N, Aguilar-Gaxiola S, Bilgen I. Translation procedures and translation assessment in the World Mental Health Survey Initiative. In: Kessler RC, Üstün TB, eds. The WHO World Mental Health Surveys: Global Perspectives on the Epidemiology of Mental Disorder. Cambridge, England: Cambridge University Press; 2008:91-113.

19. Pennell BE, Mneimneh ZN, Bowers A, et al. Implementation of the World Mental Health Surveys. In: Kessler RC, Üstün TB, eds. The WHO World Mental Health Surveys: Global Perspectives on the Epidemiology of Mental Disorder. Cambridge, England: Cambridge University Press: 2008:33-57.

20. Ruscio AM, Lane M, Roy-Byrne P, et al. Should excessive worry be required for a diagnosis of generalized anxiety disorder? results from the US National Comorbidity Survey Replication. Psychol Med. 2005;35(12):1761-1772.

21. First MB, Spitzer RL, Gibbon M, Williams JBW, eds. Structured Clinical Interview for DSM-IV-TR Axis I Disorders, Research Version, Non-patient Edition. New York: Biometrics Research Dept, New York State Psychiatric Institute; 2002.

22. Haro JM, Arbabzadeh-Bouchez S, Brugha TS, et al. Concordance of the Composite Internationa Diagnostic Interview Version 3.0 (CIDI 3.0) with standardized clinical assessments in the WHO World Mental Health Surveys. Int J Methods Psychiatr Res. 2006;15(4):167-180.

23. Lee S, Tsang A, Ruscio AM, et al. Implications of modifying the duration requirement of generalized anxiety disorder in developed and developing countries. Psychol Med. 2009;39(7): 1163-1176.

24. Ruscio AM, Chiu WT, Roy-Byrne $P$, et al. Broadening the definition of generalized anxiety disorder: effects on prevalence and associations with other disorders in the National Comorbidity Survey Replication. J Anxiety Disord. 2007;21(5): 662-676.

25. American Psychiatric Association. Diagnostic and Statistical Manual of Mental Disorders. 5th ed. Arlington, VA: American Psychiatric Association; 2013.

26. Knäuper B, Cannell CF, Schwarz N, Bruce ML, Kessler RC. Improving accuracy of major depression age-of-onset reports in the US National Comorbidity Survey. Int J Methods Psychiatr Res. 1999;8(1):39-48

27. Leon $A C$, Olfson $M$, Portera L, Farber $L$, Sheehan DV. Assessing psychiatric impairment in primary care with the Sheehan Disability Scale. Int J Psychiatry Med. 1997;27(2):93-105.

28. Merikangas KR, Akiskal HS, Angst J, et al. Lifetime and 12-month prevalence of bipolar spectrum disorder in the National Comorbidity Survey Replication. Arch Gen Psychiatry. 2007;64 (5):543-552.

29. Halli SS, Rao KV. Advanced Techniques in Population Analysis. New York: Plenum Press: 1992.

30. Shah BV. Linearization methods of variance estimation. In: Armitage P, Colton T, eds. Encyclopedia of Biostatistics. Chichester, England: John Wiley \& Sons; 1998:2276-2279.

31. SUDAAN. Professional Software for Survey Data Analysis [computer program]. Version 11.0. Research Triangle Park, NC: Research Triangle Institute; 2016
32. Grant BF, Hasin DS, Stinson FS, et al. Prevalence, correlates, co-morbidity, and comparative disability of DSM-IV generalized anxiety disorder in the USA: results from the National Epidemiologic Survey on Alcohol and Related Conditions. Psychol Med. 2005;35(12) 1747-1759.

33. Kessler RC, Berglund P, Demler O, Jin R, Merikangas KR, Walters EE. Lifetime prevalence and age-of-onset distributions of DSM-IV disorders in the National Comorbidity Survey Replication. Arch Gen Psychiatry. 2005;62(6):593-602.

34. Lawrence $A E$, Liverant $G I$, Rosellini $A J$, Brown TA. Generalized anxiety disorder within the course of major depressive disorder: examining the utility of the $D S M-I V$ hierarchy rule. Depress Anxiety. 2009;26(10):909-916.

35. Zimmerman M, Chelminski I. Generalized anxiety disorder in patients with major depression: is DSM-IV's hierarchy correct? Am J Psychiatry. 2003;160(3):504-512.

36. Coplan JD, Aaronson CJ, Panthangi V, Kim Y Treating comorbid anxiety and depression: psychosocial and pharmacological approaches. World J Psychiatry. 2015;5(4):366-378.

37. Somers JM, Goldner EM, Waraich P, Hsu L. Prevalence and incidence studies of anxiety disorders: a systematic review of the literature. Can J Psychiatry. 2006;51(2):100-113.

38. Kessler RC, Angermeyer M, Anthony JC, et al. Lifetime prevalence and age-of-onset distributions of mental disorders in the World Health Organization's World Mental Health Survey Initiative. World Psychiatry. 2007;6(3):168-176.

39. Angel $R$, Thoits $P$. The impact of culture on the cognitive structure of illness. Cult Med Psychiatry. 1987;11(4):465-494.

40. Baxter AJ, Scott KM, Vos T, Whiteford HA. Global prevalence of anxiety disorders: a systematic review and meta-regression. Psychol Med. 2013;43 (5):897-910.

41. Kessler RC, Bromet EJ. The epidemiology of depression across cultures. Annu Rev Public Health. 2013;34:119-138.

42. Hoge EA, Tamrakar SM, Christian KM, et al Cross-cultural differences in somatic presentation in patients with generalized anxiety disorder. J NerV Ment Dis. 2006;194(12):962-966.

43. Lewis-Fernández R, Hinton DE, Laria AJ, et al. Culture and the anxiety disorders: recommendations for DSM-V. Depress Anxiety. 2010;27(2):212-229.

44. Gureje O, Lasebikan VO, Kola L, Makanjuola VA. Lifetime and 12-month prevalence of mental disorders in the Nigerian Survey of Mental Health and Well-being. Br J Psychiatry. 2006;188(5): 465-471.

45. Marques L, Robinaugh DJ, LeBlanc NJ Hinton D. Cross-cultural variations in the prevalence and presentation of anxiety disorders. Expert Rev Neurother. 2011;11(2):313-322.

46. Kessler RC, Amminger GP, Aguilar-Gaxiola S, Alonso J, Lee S, Ustün TB. Age of onset of mental disorders: a review of recent literature. Curr Opin Psychiatry. 2007;20(4):359-364.

47. Lieb R, Becker E, Altamura C. The epidemiology of generalized anxiety disorder in Europe. Eur Neuropsychopharmacol. 2005;15(4):445-452. 
48. Kessler RC, Avenevoli S, Costello EJ, et al. Prevalence, persistence, and sociodemographic correlates of DSM-IV disorders in the National Comorbidity Survey Replication Adolescent Supplement. Arch Gen Psychiatry. 2012;69(4) 372-380.

49. Wittchen $\mathrm{H}-\mathrm{U}$, Nelson CB, Lachner G. Prevalence of mental disorders and psychosocial impairments in adolescents and young adults. Psychol Med. 1998;28(1):109-126.

50. Blazer D, Hughes D, George LK. Stressful life events and the onset of a generalized anxiety syndrome. Am J Psychiatry. 1987;144(9): 1178-1183.

51. Kendler KS, Hettema JM, Butera F, Gardner CO, Prescott CA. Life event dimensions of loss, humiliation, entrapment, and danger in the prediction of onsets of major depression and generalized anxiety. Arch Gen Psychiatry. 2003;60 (8):789-796

52. Monroe SM, Simons AD. Diathesis-stress theories in the context of life stress research: implications for the depressive disorders. Psychol Bull. 1991;110(3):406-425.
53. Berenbaum $\mathrm{H}$. An initiation-termination two-phase model of worrying. Clin Psychol Rev. 2010;30(8):962-975.

54. Akiskal HS. Toward a definition of generalized anxiety disorder as an anxious temperament type. Acta Psychiatr Scand Suppl. 1998;393(s393): 66-73.

55. Brown TA, Barlow DH, Liebowitz MR.

The empirical basis of generalized anxiety disorder. Am J Psychiatry. 1994;151(9):1272-1280.

56. Campbell LA, Brown TA, Grisham JR. The relevance of age of onset to the psychopathology of generalized anxiety disorder. Behav Ther. 2003;34(1):31-48.

57. Hale WW III, Klimstra TA, Meeus WHJ. Is the generalized anxiety disorder symptom of worry just another form of neuroticism? a 5-year longitudinal study of adolescents from the general population. J Clin Psychiatry. 2010;71(7):942-948.

58. Clark LA, Watson D, Reynolds $S$. Diagnosis and classification of psychopathology: challenges to the current system and future directions. Annu Rev Psychol. 1995;46:121-153.
59. Hoffman DL, Dukes EM, Wittchen H-U. Human and economic burden of generalized anxiety disorder. Depress Anxiety. 2008;25(1):72-90.

60. Kessler RC, Berglund PA, Dewit DJ, Ustün TB, Wang PS, Wittchen $\mathrm{H}-\mathrm{U}$. Distinguishing generalized anxiety disorder from major depression: prevalence and impairment from current pure and comorbid disorders in the US and Ontario. Int J Methods Psychiatr Res. 2002;11(3):99-111.

61. Wittchen $\mathrm{H}-\mathrm{U}$, Carter RM, Pfister $\mathrm{H}$ Montgomery SA, Kessler RC. Disabilities and quality of life in pure and comorbid generalized anxiety disorder and major depression in a national survey. Int Clin Psychopharmacol. 2000;15(6): 319-328.

62. Dückers MLA, Alisic E, Brewin CR A vulnerability paradox in the cross-national prevalence of post-traumatic stress disorder. $\mathrm{Br} J$ Psychiatry. 2016;209(4):300-305.

63. Luthar SS. The culture of affluence: psychological costs of material wealth. Child Dev. 2003;74(6):1581-1593. 